\title{
GESTÃO SOCIOAMBIENTAL NO CENTRO DE EDUCAÇÃO E SAÚDE DA UNIVERSIDADE FEDERAL DE CAMPINA GRANDE: UMA ANÁLISE À LUZ DA AGENDA AMBIENTAL NA ADMINISTRAÇÃO PÚBLICA
}

\author{
R. A. M. CHAVES ${ }^{1}$, M. DE F. N. BARBOSA ${ }^{2}$, J. M. C. ARAGÃO ${ }^{3}$, J. R. M. DE CARVALHO ${ }^{4}$ \\ Universidade Federal de Campina Grande \\ ORCID ID: https://orcid.org/0000-0003-3415-8829 ${ }^{1}$ \\ mfnobregabarbosa@gmail.com ${ }^{1}$
}

Submetido $23 / 03 / 2020$ - Aceito $18 / 08 / 2020$

DOI: $10.15628 /$ holos.2020.9764

\begin{abstract}
RESUMO
A pesquisa analisa a gestão socioambiental no Centro de Educação e Saúde da Universidade Federal de Campina Grande, nos moldes da Agenda Ambiental na Administração Pública (A3P). Para tanto, realiza o diagnóstico da Instituição conforme o manual da A3P específico para Universidades Públicas e, em um segundo momento, afere a percepção de 204 respondentes acerca do tema, sendo 100 alunos concluintes, 60 docentes e 44 técnico-administrativos. Os dados são analisados qualitativa e quantitativamente. Os resultados revelam que a gestão socioambiental do Centro de Educação e Saúde (CES) se encontra em estágio inicial, havendo ações isoladas, não institucionalizadas, passíveis de melhorias, como também lacunas em todos os eixos temáticos
\end{abstract}

avaliados. Inspira mais atenção a questão da sensibilização e capacitação dos servidores e alunos, além de aspectos ligados à gestão dos resíduos gerados, sobretudo os perigosos. Em contrapartida, as avaliações com maior grau de concordância por parte dos respondentes concentram-se no quinto eixo (construções públicas sustentáveis). O campus também apresenta bom desempenho em setores ligados à interação social da comunidade acadêmica, à disponibilização e ao uso de áreas verdes e à aquisição de produtos provenientes da agricultura familiar, entre outros. Em síntese, a pesquisa prepara a Instituição para o passo seguinte estabelecido pelo Manual da A3P, qual seja: elaborar o Plano de Gestão Socioambiental do CES.

PALAVRAS-CHAVE: Gestão Socioambiental, A3P, Sustentabilidade, Desenvolvimento Sustentável.

\section{SOCIO-ENVIRONMETAL MANAGEMENT AT THE EDUCATION HEALTH CENTER OF FEDERAL UNIVERSITY OF CAMPINA GRANDE: AN ANALYSIS IN THE LIGHT OF THE ENVIRONMENTAL AGENDA IN THE PUBLIC ADMINISTRATION}

\begin{abstract}
The research analyzes socio-environmental management at the UFCG Education and Health Center, along the lines of the Environmental Agenda in Public Administration (A3P). For this purpose, it carries out the diagnosis of the Institution according to the A3P manual specific to Public Universities and, in a second moment, it evaluates the perception of 204 respondents on the theme, being 100 concluding students, 60 teachers and 44 technicaladministrative. The data are analyzed qualitatively and quantitatively. The results reveal that Education and Health Center (CES) 'socio-environmental management are in initial stage, with isolated, non-institutionalized actions that can be improved, as well as gaps in all the thematic areas evaluated. It inspires more attention to the
\end{abstract}

issue of raising awareness and training of civil servants and students, in addition to aspects related to the management of waste generated, especially hazardous ones. In contrast, the assessments with the highest degree of agreement on the part of respondents are concentrated on the fifth axis (sustainable public constructions). The campus also performs well in sectors linked to the social interaction of the academic community, the provision and use of green areas and the purchase of products from family farming, among others. In summary, the research prepares the Institution for the next step established by the A3P Manual, namely: to elaborate the CES Social and Environmental Management Plan. 


\section{APRESENTAÇÃO}

A gestão voltada para as causas ambientais e como ela evoluiu para o estágio tal qual conhecemos hoje - alinhada ao desenvolvimento sustentável e à sustentabilidade, admitindo um caráter de conciliação entre o meio ambiente e os anseios das pessoas - pauta inúmeras discussões ao redor do mundo, envolvendo lideranças políticas, corporações empresariais, cientistas, ativistas e a sociedade em geral.

Nesse sentido, ao longo do século $X X$, houve a necessidade de promover melhorias significativas quanto ao controle ambiental dos ecossistemas urbanos, aperfeiçoando, gradativamente, os conceitos de desenvolvimento sustentável e sustentabilidade (Seiffert, 2014). Este último, tomando como orientação o pensamento de Sartori, Latrônico e Campos (2014), é um princípio aplicável a vários sistemas, inclusive os industriais, sociais e naturais, abarcando os fluxos de informações, bens, materiais, resíduos, etc.

Apresentado ao mundo oficialmente pela Comissão Mundial do Meio Ambiente e Desenvolvimento, após publicação do Relatório Brundtland, e ratificado pela Agenda 21, durante a Conferência Rio-92, o termo desenvolvimento sustentável estabelece que a busca da satisfação imediata, desde as necessidades básicas até as aspirações por uma vida melhor, não devem comprometer as gerações futuras de satisfazerem suas próprias necessidades (Comissão Mundial sobre Meio Ambiente e Desenvolvimento [CMMAD], 1991). Ou seja, usufrui-se dos recursos disponíveis de maneira a possibilitar que as próximas gerações também o façam.

Nessa perspectiva, atendendo às recomendações da Agenda 21, foi concebida a Agenda Ambiental na Administração Pública (A3P) (Brasil, 2017a). Tal programa visa "estimular a ética e promover a autoestima dos servidores públicos; e a mudança de atitude dos servidores públicos para que os mesmos incorporem os critérios de gestão socioambiental em suas atividades rotineiras" (Brasil, 2017b, p. 12). Kruger, Freitas, Pfitscher e Petri (2011), em estudo realizado junto a uma IFES, alerta para a importância da aderência dessas organizações à A3P devido à sua capacidade de influenciar positivamente o seu contexto social. Assim, por serem celeiros de produção e disseminação do conhecimento, as Universidades configuram um espaço ideal para a implantação da A3P (Brasil, 2017b).

A coleta de dados da presente pesquisa ocorre no Centro de Educação e Saúde da Universidade Federal de Campina Grande (UFCG). Referência na microrregião do Curimataú Ocidental Paraibano, o Centro de Educação e Saúde (CES) é um dos onze Centros da UFCG, sendo o segundo maior campus fora de sede em número de alunos matriculados (1727) e professores (127), de acordo com dados da Pró-Reitoria de Ensino (PRE), no segundo semestre de 2019. Oferece o Mestrado Acadêmico em Ciências Naturais e Biotecnologia, além de sete cursos de graduação, divididos entre quatro licenciaturas e três bacharelados. Ademais, conta com o apoio de 46 servidores técnico-administrativos em seu quadro funcional. Seguindo essa linha, busca-se aprofundar os conhecimentos acerca da percepção dos principais atores que vivenciam diariamente suas rotinas no $\mathrm{CES}$. 
Visando ao esclarecimento mais consistente dos temas supracitados e no intuito de contribuir com a literatura no entorno da gestão socioambiental, sobretudo no que tange às implicações que a A3P sugere em relação às Instituições Federais de Ensino Superior (IFES), este estudo propõe investigar a seguinte problemática: como a Gestão Socioambiental é desenvolvida no Centro de Educação e Saúde da UFCG sob a perspectiva da Agenda Ambiental na Administração Pública (A3P)? E tem como objetivo geral analisar a gestão socioambiental no Centro de Educação e Saúde da UFCG nos moldes da Agenda Ambiental na Administração Pública (A3P).

\section{REVISÃO BIBLIOGRÁFICA}

\subsection{Desenvolvimento sustentável}

Tratado como o documento que amplificou os debates e as iniciativas acerca das questões ambientais, o Relatório de Brundtland, publicado originalmente em 1987 após uma conferência que reuniu a Comissão Mundial sobre o Meio Ambiente e Desenvolvimento, assevera que "desenvolvimento sustentável é aquele que atende às necessidades do presente sem comprometer a possibilidade de as gerações futuras atenderem a suas próprias necessidades" (CMMAD, 1991, p. 46).

Sob essa ótica, a preocupação com o desenvolvimento sustentável salta da utopia e assume estrategicamente o comando das ações fundamentais para a sobrevivência da espécie humana (Dias, 2004). Esse sentido amplo atribuído à palavra "sobrevivência", especialmente a partir do século XXI, impõe ao ser humano o enfrentamento das consequências emersas das transformações dos elementos naturais (Cogo, Oliveira, \& Tesser, 2012). Tem-se, portanto, a consignação de um "processo variável de mudança que busca como objetivo final a sustentabilidade" (Sartori, Latrônico, \& Campos, 2014, p. 3).

\subsection{Sustentabilidade}

Para compreender a sustentabilidade há que se considerar duas premissas: os recursos naturais não são infinitos; e não é possível rumar em direção ao futuro indefinidamente como se houvesse uma reserva de progresso ilimitada (Boff, 2013). Isso passa por praticar a agricultura sustentável, proteger as florestas e outros habitats, tornar sustentável o uso de energia, praticar o uso sustentável da água e reduzir a geração de lixo (Seiffert, 2014).

Com isso, entende-se que não há outro caminho que leve à redução da degradação ambiental, senão conduzir o indivíduo a uma profunda reflexão, de modo a sensibilizá-lo. Nesse sentido, Cogo, Oliveira e Tesser (2012, p. 2) realçam que a sustentabilidade busca "garantir a disponibilidade dos recursos da Terra hoje, assim como para nossos descendentes, por meio de uma gestão que contemple a proteção ambiental, a justiça social e o desenvolvimento econômico equilibrado de nossas sociedades". 


\subsection{Gestão socioambiental}

A gestão socioambiental apresenta-se como uma matéria que concatena conceitos ligados a uma nova forma de pensar as organizações. Tomando por base o manual de Gestão Socioambiental nas Universidades Públicas (Brasil, 2017a, p. 17), este tipo de gerenciamento, com ênfase na sustentabilidade, "visa o uso de métodos e práticas de gestão que minimize o máximo de impacto ambiental das atividades econômicas nos recursos naturais, proporcionando uma melhor qualidade de vida socioambiental".

Em se tratando das universidades públicas, pelo fato das suas ações terem um efeito multiplicador, a adoção desse arquétipo de gestão, inclusive com a inserção de disciplinas que tratem do tema, sinaliza à comunidade acadêmica a intenção da instituição em promover uma economia de recursos, ao passo que melhora a qualidade de vida dos atores sociais envolvidos e reduz os impactos sobre o meio ambiente local de forma direta (Brasil, 2017a).

\subsection{Agenda ambiental na administração pública (A3P)}

A A3P foi materializada no ano de 1999 e prevê a construção, a partir de um processo participativo, de ações ambientais que possibilitem às instituições fazer frente às questões de sustentabilidade (Cogo et al., 2012). O principal foco definido pela A3P é "estimular a ética e promover a autoestima dos servidores públicos; e a mudança de atitude dos servidores para que os mesmos incorporem os critérios de gestão ambiental em suas atividades rotineiras" (Brasil, 2017b, p. 12).

\subsubsection{Eixos Temáticos da A3P}

\subsubsection{Eixo 1 - Uso Racional dos Recursos Naturais e Bens Públicos}

O primeiro eixo da A3P diz respeito ao uso racional dos recursos naturais e bens públicos. É dedicado a tópicos que tratam da utilização de papel e material de expediente, bem como ao consumo consciente de energia e água (Brasil, 2001). Cogo et al. (2012) endossam esse raciocínio quando esclarecem que um dos focos é evitar o consumo excessivo de papel e copos plásticos, bem como reciclar lâmpadas fluorescentes, a fim de mitigar os riscos de contaminação por mercúrio, e preferir outras opções mais econômicas a estas.

\subsubsection{Eixo 2 - Gestão de Resíduos Gerados}

Este eixo se comunica diretamente com a política dos 5R's (Repensar, Reduzir, Reutilizar, Reciclar e Recusar) que objetiva a redução de desperdício por meio da educação ambiental (Cogo et al., 2012). Desta forma, sugere-se que o gestor faça algumas reflexões: "a universidade precisa disso? Qual a quantidade? Qual o melhor produto? Qual o produto que traz menos impactos ambientais?" (Brasil, 2017a, p. 16). A Política Nacional de Resíduos Sólidos (Lei no 12.305/2010), por sua vez, sentencia uma ordem de prioridade a ser seguida: não geração, redução, reutilização, reciclagem, tratamento dos resíduos sólidos e disposição final ambientalmente adequada dos rejeitos (Brasil, 2010a). 


\subsubsection{Qualidade de Vida no Ambiente de Trabalho}

Falar de qualidade de vida no ambiente de trabalho implica em considerar o desenvolvimento pessoal e profissional do trabalhador por meio da satisfação das suas necessidades inerentes à subjetividade humana (Brasil, 2009). De maneira simples, este eixo da A3P se destina a buscar uma melhoria na qualidade de vida, na saúde e segurança no trabalho, além de se preocupar com a formação continuada dos servidores públicos em relação aos aspectos ambientais e à interação com seus pares, clientes e a sociedade como um todo (Cogo et al., 2012).

\subsubsection{Eixo 4 - Sensibilização e Capacitação dos Servidores}

A sensibilização dos servidores percorre o caminho da própria percepção em torno da responsabilidade socioambiental, como também pretende "revelar a urgência e necessidade de adoção de práticas que promovam a preservação ambiental e o respeito à vida, a partir do local de trabalho" (Brasil, 2017a, p. 16). Assim, um dos principais desafios à eficácia da A3P diz respeito à conscientização dos gestores, no sentido de tornar eficiente o trabalho realizado em termos de utilização de recursos naturais e adoção de boas práticas de sustentabilidade em suas organizações (Pegorin, Santos, \& Martins, 2014).

\subsubsection{Compras Públicas Sustentáveis}

O Ministério do Meio Ambiente (Brasil, 2009) repercute que a administração pública deve promover a responsabilidade socioambiental das suas compras, pois demanda produtos e serviços sustentáveis, combinando a conservação do meio ambiente com a melhor relação custo/benefício em termos de preço e durabilidade, em detrimento de optar exclusivamente pelo preço no escopo do certame licitatório. Como bem lembra o Ministério do Meio Ambiente (Brasil, 2017a), a condicionante "menor preço", quando não utilizada com parcimônia, pode representar mais resíduos e mais problemas ambientais, concomitantemente nos âmbitos financeiro e social.

\subsubsection{Eixo 5 - Construções, Reformas e Ampliações Sustentáveis}

Este eixo trata como prioridade a contratação de mão-de-obra, materiais, tecnologias e matérias-primas de origem local; além de exigir que o licitante seja certificado quanto a práticas de desfazimento sustentável ou reciclagem dos bens que forem inservíveis para o processo de reutilização (Brasil, 2010b). Nessa lógica, a manual de Gestão Socioambiental nas Universidades Públicas também apresenta algumas soluções práticas: a madeira deve ser certificada; o telhado não deve ser de amianto; as torneiras devem ter corte automático de vazão; a estrutura predial deve eleger o uso da luz natural (Brasil, 2017a).

\subsection{Análise de estudos correlatos}

Freitas, Borget e Pfitscher (2011), a partir de um check-list adaptado do MMA, propuseram analisar a aderência de uma IFES às diretrizes propostas pela A3P. Os resultados mostraram uma adesão parcial, vistas as lacunas respeitantes à sensibilização dos gestores e da comunidade 
acadêmica (stakeholders internos e externos), promoção de licitações sustentáveis e gestão adequada dos resíduos sólidos.

Pegorin, Santos e Martins (2014) dispuseram-se a examinar como a A3P contribui para o desenvolvimento de práticas sustentáveis no ambiente organizacional de uma entidade pública. Foi constatado que a grande maioria dos servidores tinha conhecimento da implantação da Agenda e que esta contribuía para mitigar os impactos decorrentes do desempenho de suas funções. Contudo, quase metade dos entrevistados não replicava tais recomendações, nem no ambiente laboral e tampouco fora dele.

Viegas e Cabral (2014), utilizando modelo de check-list elaborado por Freitas et al. (2011), em consulta a gestores de uma organização, notaram que a qualidade de vida no ambiente de trabalho e a sensibilização e capacitação dos servidores proporcionaram maior nível de aderência; por outro lado, itens relacionados à destinação de resíduos gerados, à utilização dos recursos naturais e às compras públicas, contribuíram para o panorama de não adequação total ao programa.

Dias (2014), em estudo na Universidade Federal da Bahia, identificou algumas práticas em consonância com a A3P, mas que precisavam estender seu alcance a fim de se adequarem à gestão ambiental desejada pela sociedade. Na visão da autora, a falta de institucionalização dos programas e projetos representa o maior desafio à incorporação da sustentabilidade como princípio elementar na estrutura organizacional daquela IFES.

De forma mais abrangente, Araújo, Freitas e Rocha (2017) compuseram um estudo de práticas sustentáveis em conformidade com a A3P que contemplou integralmente uma Universidade Federal de estrutura multicampi. Ao entrevistarem prefeitos dos campi, os autores descobriram que apenas dois dos sete campi dispõem de um Plano de Gestão Ambiental (PGA) e somente um deles está em consonância com a A3P.

Gondim (2017), tomando por base o contexto do Centro de Ciências Médicas da UFPB, observou a incipiência da sensibilização e capacitação socioambiental dos servidores, a fim de estimular a conscientização sobre as práticas sustentáveis como um todo. Do mesmo modo que identificado nos resultados relativos ao estudo anterior, comprovou-se que o local pesquisado "adere boa parte dos objetivos e eixos da A3P, porém o mesmo não possui uma política ambiental com propostas sobre práticas sustentáveis" (Gondim, 2017, p. 7).

\section{METODOLOGIA}

No que tange à formulação dos objetivos propostos, este estudo caracteriza-se como descritivo. Seus dados secundários são fundamentalmente de fonte bibliográfica. Lança-se mão de dois tipos de instrumentos de coleta de dados: o formulário extraído do manual de Gestão Socioambiental nas Universidades Públicas, composto de seis blocos, um para cada eixo da A3P, aplicado junto ao Prefeito Setorial do campus, Nutricionista do Restaurante Universitário, Chefes do Almoxarifado, do Patrimônio e do Setor de Licitações, Diretor do campus e um Professor coordenador de um projeto local; e questionários, concebidos a partir do formulário referenciado, 
destinados a três categorias de respondentes: servidores técnico-administrativos, professores e alunos concluintes.

A coleta considera a população constante nas classes dos professores (127) e servidores técnico-administrativos (44), tendo sido excluídos o Prefeito Universitário e o autor da pesquisa, enquanto o grupo dos discentes participa por meio dos alunos concluintes de cada curso, totalizando 100 indivíduos. Foram enviados 271 questionários, dos quais 204 retornaram: 100 alunos concluintes, 60 docentes e 44 servidores técnico-administrativos.

As técnicas escolhidas para tratamento dos dados primários são as qualitativa e quantitativa. Tais procedimentos "não se opõem então e podem até parecer complementares, cada uma ajudando à sua maneira o pesquisador a cumprir sua tarefa" (Laville \& Dionne, 1999, p. 225). Para Marconi e Lakatos (2007), a abordagem qualitativa possibilita a chance de que um conteúdo empírico determinado seja controlado por elementos observacionais; ao passo que Creswell (2007, p. 35), sugere que o viés quantitativo "emprega estratégias de investigação como experimentos, levantamentos e coleta de dados, instrumentos predeterminados que geram dados estatísticos".

\section{RESULTADOS E DISCUSSÃO}

O primeiro ciclo se dedica ao exame do formulário aplicado junto ao Prefeito Setorial; à Nutricionista do Restaurante Universitário; aos Chefes do Almoxarifado, Patrimônio, Divisão de Materiais e Setor de Licitações; ao Diretor do campus e a um Professor coordenador de um projeto local, de forma a captar informações sobre a real situação do CES. Em um segundo momento, o estudo afere a percepção dos respondentes - servidores técnico-administrativos, professores e alunos concluintes - em relação às práticas desenvolvidas no âmbito da gestão socioambiental no CES.

\subsection{A A3P no centro de educação e saúde}

\subsubsection{Eixo Temático 1 - Evidências Observadas}

Constatou-se que o CES não verifica nem possui equipamento para aferir o consumo mensal de água (q1) em suas dependências. O sistema de irrigação presente no CES não dispõe de automação, competindo aos próprios jardineiros o controle manual da vazão da água. As práticas relatadas que colaboram para a redução do consumo de água (q5) são basicamente três: aproveitamento de água resultante da atividade de aparelhos de ar condicionado nos Blocos de Aula (G e I); afixar cartazes em ambientes estratégicos e ações pontuais de conscientização em eventos, oficinas, debates, rodas de conversa e assembleias.

No tocante à verificação do consumo mensal de energia elétrica (q2), somente a partir de janeiro de 2019, quando em uma mudança de fluxo processual, o campus passou a ter acesso à fatura mensal. As práticas orientadas para reduções no consumo de energia (q6) referem-se à suspensão das atividades noturnas no complexo esportivo; não ativar a iluminação externa em áreas tidas como não essenciais e a substituição das lâmpadas fluorescentes convencionais pelas de LED. 
Quanto ao consumo mensal de papel (q3) e copos descartáveis (q4), o CES mantém o controle do consumo destes itens desde a sua fundação. No que tange às práticas voltadas para a redução do consumo destes (q7 e q8) no CES, o chefe do Almoxarifado indicou que as conversas pontuais com os demandantes são as únicas atitudes constatadas para reduzir as saídas do material.

\subsubsection{Eixo Temático 2 - Evidências Observadas}

No primeiro questionamento (q9) foi identificado que o CES realiza a separação dos resíduos em conformidade com a Resolução CONAMA no 275. Porém, a etapa de destinação final ocorre de maneira imprópria e rudimentar. No caso de papéis e papelões, são armazenados até que um catador local os recolha e se encarregue da reciclagem. Com relação à separação de resíduos perigosos (q10), o CES não detém uma estrutura adequada para o descarte: as lâmpadas fluorescentes substituídas são acondicionadas em caixas de madeira construídas para este fim, os resíduos gerados pelos laboratórios em bombonas (galões de plástico) e os materiais de informática seguem para descarte no lixo comum.

No tocante ao descarte de bens inservíveis como equipamentos eletroeletrônicos e de sala de aula (q11), nunca houve o desfazimento de bens permanentes/tombados, sendo encaminhados para um depósito nas dependências do CES. A realização de compostagem de resíduos orgânicos (q12) ocorre por intermédio do "Projeto de Reflorestamento do Olho D'água da Bica" que reaproveita parcialmente o material orgânico/vegetal proveniente do Restaurante Universitário (RU) para ações de reflorestamento e adubação. Formalmente, inexistem práticas direcionadas à redução da utilização de materiais de expediente (q13).

\subsubsection{Eixo Temático 3 - Evidências Observadas}

As ações relacionadas ao tema se notabilizam em eventos acadêmicos, abertos ao público, oferecidos pela universidade, como a oficina de Produção e Plantio de Mudas de Árvores Nativas da Caatinga do Município de Cuité-PB. Outrossim, desde o ano de 2015, o programa "Horto Florestal Olho D'água da Bica CES/UFCG: educação ambiental, recuperação ambiental e sustentabilidade" promove capacitação de alunos, alguns funcionários do campus e a comunidade em geral (Universidade Federal de Campina Grande, 2019).

\subsubsection{Eixo Temático 4 - Evidências Observadas}

Concernente à realização de projetos de educação ambiental (q15) e eventos com a comunidade do entorno sobre sustentabilidade socioambiental (q16), vale mencionar o programa "Horto Florestal Olho D'água da Bica CES/UFCG: educação ambiental, recuperação ambiental e sustentabilidade" que, além das atitudes já relatadas, desenvolve atividades junto à comunidade sobre educação ambiental relacionadas à identificação, cultivo e plantio de árvores nativas (Universidade Federal de Campina Grande, 2019).

O CES possui bicicletário (q17) em suas dependências com capacidade para comportar o mínimo de 8 bicicletas. Os equipamentos de esporte e lazer do CES (q18) apresentam bom estado de preservação, além de serem constantemente utilizados. A estrutura conta com ginásio 
poliesportivo, academia ao ar livre, quadra de tênis, campo de futebol society, pista para caminhada de cerca de $400 \mathrm{~m}$ e duas quadras de areia.

Com relação à acessibilidade, o CES tem rampas de acesso, mas não possui elevadores (q19). Há um total de vinte e cinco rampas, onze das quais sem sinalização e uma sem corrimão de apoio. No tocante à oportunização de equipamentos adequados a portadores de necessidades especiais (q20), há estacionamentos privativos posicionados estrategicamente pelo campus, corrimões de segurança em áreas de passeio e computadores com tela e caracteres ampliados destinados ao usuário com deficiência parcial da visão.

O CES possui equipamentos (corrimões) de proteção nas escadas (q21) dos seus prédios. Não há horta (q22) e pomar (q26) controlados pela universidade. O CES não realiza a compra de alimentos orgânicos (q24), visto que, na visão dos gestores, os preços são sensivelmente mais elevados que os tradicionais. Quanto à compra de alimentos provenientes da agricultura familiar (q25), o CES tem adquirido hortifrutigranjeiros e polpa de frutas oriundos exclusivamente deste segmento de agricultores. O CES não mantém criação de animais (bovinos, caprinos, suínos, aves e outros) (q27) em suas dependências.

\subsubsection{Eixo Temático 5 - Evidências Observadas}

Os dois primeiros questionamentos do quinto bloco examinam se o CES faz uso de fonte alternativa de energia renovável (q28) e se possui aquecedor solar (29). A começar pelo último, a própria conjuntura climática dispensa o uso desta tecnologia. Os custos elevados para a implantação de sistema de energia solar fotovoltaica e a ausência de pessoal qualificado no campus emperram as discussões em torno do assunto.

O CES conserva em suas dependências uma cisterna, em pleno funcionamento, com capacidade de armazenamento para 120 mil litros (q30). As dependências do CES não são ligadas à rede pública de saneamento (q31). Evidenciou-se que todas as salas de aula do CES são equipadas com janelas para ventilar (q32), que a regra no campus é usar a luz natural em detrimento da artificial (q33) e que as janelas permanecem a maior parte do tempo fechadas em razão das salas de aula serem climatizadas (q34).

A estrutura predial das salas de aula segue um modelo convencional de construção, não havendo qualquer proteção específica contra ruídos externos (q35). Acerca da madeira utilizada no mobiliário do CES (q36), a partir do Pregão Eletrônico no 02/2018, o CES passou a exigir que o fabricante estivesse regularmente registrado no Cadastro Técnico Federal de Atividades Potencialmente Poluidoras ou Utilizadoras de Recursos Ambientais, sob a administração do Instituto Brasileiro do Meio Ambiente e dos Recursos Naturais Renováveis (IBAMA).

O CES pratica o uso de material ou equipamento reciclado ou reutilizado (q37), ainda que de forma incipiente, para fins de ornamentação do campus. Sua área, preservada pela vegetação nativa do Bioma Caatinga, é repleta de jardins e zonas verdes (q38), inclusive dentro do próprio campus há o Olho D'água da Bica, um espaço aberto à visitação do público em geral, além de três praças que acomodam diversos tipos de atividades (q39). 


\subsubsection{Eixo Temático 6 - Evidências observadas}

A realização de licitações para compra de produtos ou contratação de serviços e obras sustentáveis (q40) é algo recente na realidade do CES. Somente no fim de 2018, passou-se a observar critérios de sustentabilidade de forma programática nos editais. Para tanto, a Divisão de Materiais utiliza um manual de compras públicas sustentáveis elaborado pela Advocacia Geral da União (AGU), a fim de conferir segurança jurídica ao procedimento.

\subsection{A percepção de alunos concluintes, professores e técnico-administrativos acerca da} Gestão Socioambiental no CES

\subsubsection{Síntese das Percepções dos Respondentes}

Apresenta-se nesta seção um quadro-síntese relacionando os segmentos pesquisados: alunos concluintes, professores e servidores técnicos-administrativos. Traça-se um paralelo da predominância do grau de concordância, discordância ou indiferença, e suas respectivas variáveis avaliadas (Quadro 1), em comparação à realidade encontrada no diagnóstico discorrido na primeira etapa da análise de dados.

Quadro 1: Resumo das percepções predominantes dos respondentes segundo as categorias

\begin{tabular}{|c|c|c|c|c|}
\hline \multirow[b]{2}{*}{ Eixos Temáticos - Questões } & \multicolumn{3}{|c|}{ Categorias } & \multirow{2}{*}{$\begin{array}{c}\text { Evidênc } \\
\text { ia } \\
\text { observa } \\
\text { da no } \\
\text { CES }\end{array}$} \\
\hline & Alunos & Professores & Servidores & \\
\hline \multicolumn{5}{|l|}{$\begin{array}{l}\text { Eixo } 1 \text { - Uso Racional dos Recursos Naturais e Bens } \\
\text { Públicos }\end{array}$} \\
\hline 1. A universidade verifica mensalmente o consumo de água? & & & & $\begin{array}{l}\text { Parcial } \\
\text { mente }\end{array}$ \\
\hline 2. A universidade verifica mensalmente o consumo de energia? & & & & Sim \\
\hline 3. A universidade verifica mensalmente o consumo de papel? & & & & Sim \\
\hline $\begin{array}{l}\text { 4. A universidade verifica mensalmente o consumo de copos } \\
\text { descartáveis? }\end{array}$ & & & & Sim \\
\hline $\begin{array}{l}\text { 5. A universidade adota alguma prática para reduzir o consumo de } \\
\text { água? }\end{array}$ & & & & Não \\
\hline $\begin{array}{l}\text { 6. A universidade adota alguma prática para reduzir o consumo de } \\
\text { energia? }\end{array}$ & & & & Sim \\
\hline $\begin{array}{l}\text { 7. A universidade adota alguma prática para reduzir o consumo de } \\
\text { papel? }\end{array}$ & & & & Não \\
\hline $\begin{array}{l}\text { 8. A universidade adota alguma prática para reduzir o consumo de } \\
\text { copos descartáveis? }\end{array}$ & & & & Não \\
\hline \multicolumn{5}{|l|}{ Eixo 2 - Gestão Adequada dos Resíduos Gerados } \\
\hline 9. A universidade separa os resíduos sólidos recicláveis? & & & & Sim \\
\hline 10. A universidade separa resíduos perigosos? & & & & $\begin{array}{l}\text { Parcial } \\
\text { mente }\end{array}$ \\
\hline $\begin{array}{l}\text { 11. A universidade descarta bens inservíveis como: } \\
\text { eletroeletrônicos, fogão, geladeira, freezer, carteiras }\end{array}$ & & & & Não \\
\hline
\end{tabular}


Quadro 1: Resumo das percepções predominantes dos respondentes segundo as categorias

\begin{tabular}{|c|c|c|c|c|}
\hline \multirow[b]{2}{*}{ Eixos Temáticos - Questões } & \multicolumn{3}{|c|}{ Categorias } & \multirow{2}{*}{$\begin{array}{c}\text { Evidênc } \\
\text { ia } \\
\text { observa } \\
\text { da no } \\
\text { CES }\end{array}$} \\
\hline & Alunos & Professores & Servidores & \\
\hline $\begin{array}{l}\text { escolares, cadeiras, mesas, escrivaninhas, panelas, lousas e } \\
\text { outros? }\end{array}$ & & & & \\
\hline 12. A universidade realiza a compostagem de resíduos orgânicos? & & & & Sim \\
\hline $\begin{array}{l}\text { 13. A universidade adota práticas para redução do material de } \\
\text { expediente (lápis, caneta, papel, pincel atômico, cartucho de } \\
\text { impressora, outros)? }\end{array}$ & & & & Não \\
\hline \multicolumn{5}{|l|}{ Eixo 3 - Sensibilização e Capacitação dos Servidores } \\
\hline $\begin{array}{l}\text { A universidade promove capacitação de alunos, professores, } \\
\text { funcionários e pais dos alunos, sobre questões ambientais? }\end{array}$ & & & & $\begin{array}{l}\text { Minima } \\
\text { mente }\end{array}$ \\
\hline \multicolumn{5}{|l|}{$\begin{array}{l}\text { Eixo } 4 \text { - Qualidade de Vida no Ambiente de Trabalho e } \\
\text { Estudo }\end{array}$} \\
\hline 17. A universidade realiza projetos de educação ambiental? & & & & $\begin{array}{l}\text { Ações } \\
\text { isoladas }\end{array}$ \\
\hline $\begin{array}{l}\text { 18. A universidade promove eventos com a comunidade do } \\
\text { entorno sobre sustentabilidade socioambiental? }\end{array}$ & & & & $\begin{array}{l}\text { Ações } \\
\text { isoladas }\end{array}$ \\
\hline 19. A universidade tem bicicletário? & & & & Sim \\
\hline $\begin{array}{l}\text { 20. Os equipamentos de esporte e lazer são preservados e } \\
\text { utilizados? }\end{array}$ & & & & Sim \\
\hline $\begin{array}{l}\text { 21. A universidade tem rampas de acesso ou elevador para } \\
\text { deficientes? }\end{array}$ & & & & Sim \\
\hline $\begin{array}{l}\text { 22. A universidade tem equipamentos adequados à portadores de } \\
\text { necessidades especiais? }\end{array}$ & & & & $\begin{array}{l}\text { Parcial } \\
\text { mente }\end{array}$ \\
\hline $\begin{array}{l}\text { 23. A universidade possui equipamentos de proteção nas } \\
\text { escadas? }\end{array}$ & & & & Sim \\
\hline 24. A universidade possui uma horta? & & & & Não \\
\hline 25. A horta é utilizada nas refeições? & & & & - \\
\hline 26. A universidade compra alimentos orgânicos? & & & & Não \\
\hline 27. A universidade compra alimentos da agricultura familiar? & & & & Sim \\
\hline 28. A universidade tem pomar? & & & & Não \\
\hline $\begin{array}{l}\text { 29. A universidade tem criação de animais (bovinos, caprinos, } \\
\text { suínos, aves e outros)? }\end{array}$ & & & & Não \\
\hline \multicolumn{5}{|l|}{$\begin{array}{l}\text { Eixo } 5 \text { - Construções, Reformas e Ampliações } \\
\text { Sustentáveis }\end{array}$} \\
\hline $\begin{array}{l}\text { 30. A universidade faz uso de fonte alternativa de energia } \\
\text { renovável? }\end{array}$ & & & & Não \\
\hline 31. A universidade possui aquecedor solar? & & & & Não \\
\hline $\begin{array}{l}\text { 32. A universidade tem estrutura para captação e uso de água da } \\
\text { chuva? }\end{array}$ & & & & Sim \\
\hline 33. Essa estrutura está em uso? & & & & Sim \\
\hline 34. A universidade está ligada à rede pública de saneamento? & & & & Não \\
\hline 35. As salas de aula têm janelas para ventilar? & & & & Sim \\
\hline $\begin{array}{l}\text { 36. As salas de aula usam de forma eficiente a iluminação } \\
\text { natural? }\end{array}$ & & & & Sim \\
\hline
\end{tabular}


Quadro 1: Resumo das percepções predominantes dos respondentes segundo as categorias

\begin{tabular}{|c|c|c|c|c|}
\hline \multirow[b]{2}{*}{ Eixos Temáticos - Questões } & \multicolumn{3}{|c|}{ Categorias } & \multirow{2}{*}{$\begin{array}{c}\text { Evidênc } \\
\text { ia } \\
\text { observa } \\
\text { da no } \\
\text { CES }\end{array}$} \\
\hline & Alunos & Professores & Servidores & \\
\hline $\begin{array}{l}\text { 37. As salas de aula têm janelas, mas não usam, por serem } \\
\text { climatizadas? }\end{array}$ & & & & Sim \\
\hline $\begin{array}{l}\text { 38. As salas de aula possuem algum tipo de parede de proteção } \\
\text { contra ruídos externos? }\end{array}$ & & & & Não \\
\hline 39. O mobiliário da universidade é de madeira certificada? & & & & $\begin{array}{l}\text { Parcial } \\
\text { mente }\end{array}$ \\
\hline $\begin{array}{l}\text { 40. A universidade faz uso de material ou equipamento reciclado } \\
\text { ou reutilizado? }\end{array}$ & & & & $\begin{array}{l}\text { Parcial } \\
\text { mente }\end{array}$ \\
\hline 41. A universidade possui jardim? & & & & Sim \\
\hline 42. Existe praça ou parque próximo da universidade? & & & & Sim \\
\hline 43. O CES/UFCG utiliza essa praça ou parque? & & & & Sim \\
\hline \multicolumn{5}{|l|}{ Eixo 6 - Contratações Públicas Sustentáveis } \\
\hline $\begin{array}{l}\text { 44. A universidade realiza licitações para compra de produtos ou } \\
\text { contratação de obras e serviços sustentáveis? }\end{array}$ & & & & $\begin{array}{l}\text { Parcial } \\
\text { mente }\end{array}$ \\
\hline
\end{tabular}

Legenda: Discordância

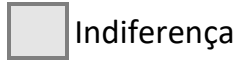

Concordância

Respeitante ao uso racional dos recursos naturais e bens públicos, o CES apresenta um quadro de monitoramento incipiente quanto ao consumo de água, energia, papel e copos descartáveis. Os resultados da investigação no que tange à percepção dos respondentes revelaram que os alunos têm uma maior predisposição a concordarem com tais temas, ao passo que professores e técnicos alternam entre concordância e discordância.

Com relação à gestão adequada dos resíduos gerados, percebe-se que enquanto a compostagem de resíduos orgânicos, graças à dinâmica do programa “Horto Florestal Olho D'água da Bica CES/UFCG: educação ambiental, recuperação ambiental e sustentabilidade", é realizada com êxito, os bens inservíveis, resíduos sólidos recicláveis e os perigosos têm fluxo distinto do desejado. Servidores técnico-administrativos, professores e alunos foram consensuais ao concordarem que o CES separa resíduos recicláveis e perigosos.

No terceiro eixo ficou evidenciado que as ações existentes são lideradas pelo programa supracitado, direcionadas a alunos e alguns servidores, mas não há a institucionalização dessas práticas. Um reflexo disso foi detectado nas respostas da comunidade acadêmica, pois as três categorias foram enfáticas ao discordarem da assertiva que trata da promoção de capacitação pelo CES respeitante a temas ambientais.

Os questionamentos do quarto eixo mostram que o CES caminha para uma mudança de paradigma, percebida na aquisição de produtos provenientes da agricultura familiar e, apesar de não comprar alimentos orgânicos, na permissão de agricultores locais comercializem produtos desta natureza nas dependências do campus. Apenas os técnicos asseguraram que a universidade compra 
alimentos da agricultura familiar, sinalizando que tal informação não chegou ao restante da comunidade acadêmica.

O quinto eixo averiguou a situação das construções, reformas e ampliações sustentáveis. Há uma boa estrutura de captação de água em uso, garantindo a autossuficiência dos bebedouros o ano inteiro. Parte do mobiliário da Instituição é de madeira certificada, prática que pretende ser estendida à medida que a demanda por novos móveis surja. Jardins, praças e parques são aproveitados principalmente como espaços de interação social.

As contratações públicas sustentáveis - sexto eixo - indicaram o cumprimento parcial dos critérios de sustentabilidade. As aquisições de produtos têm contemplado estas características, o que deve ser intensificado nas próximas licitações. As contratações de obras e serviços, muito por conta dos custos elevados e da própria legislação, ainda não seguem padrões de sustentabilidade. Respeitante a esta temática, apenas os alunos concordaram com a afirmação proposta, ao passo que professores e técnicos se mantiveram neutros.

\section{CONCLUSÃO}

A pesquisa analisou como a Gestão Socioambiental é desenvolvida no CES sob a perspectiva da A3P. Para isto, espelhando-se em estudos correlatos, identificou as práticas socioambientais do campus. Feito isto, visando ao incremento científico e à reavaliação de práticas e elaboração de ações, aferiu-se a percepção dos servidores técnico-administrativos, professores e alunos concluintes acerca da gestão socioambiental do CES. As principais limitações são verificadas no baixo retorno de questionários dos docentes (50\%), pois deixa-se de conhecer a percepção de 67 professores que poderiam enriquecer os resultados da pesquisa, e na abordagem utilizada, no sentido de que investiga-se o "como" as coisas acontecem, mas não se apura o "porquê" delas acontecerem.

A partir das informações coletadas e analisadas, conclui-se que a gestão socioambiental desenvolvida no CES encontra-se em estágio inicial, com sinais positivos em áreas que primam pela realização de licitações para compra de produtos sustentáveis e provenientes da agricultura familiar, por práticas extracurriculares integrativas, estímulo à interação social entre a comunidade acadêmica e a sociedade, utilização coletiva dos espaços comuns, preservação e recuperação de áreas verdes, disponibilização de equipamentos para prática de esportes e lazer, captação de águas pluviais, utilização da luz natural nos ambientes, monitoramento do consumo de bens públicos e compostagem de resíduos orgânicos.

Por outro lado, essencialmente em relação à sensibilização e capacitação dos atores organizacionais, há um território a ser conquistado por meio de práticas voltadas para o uso adequado de bens públicos, especialmente papel e copos descartáveis; coleta, armazenamento e descarte de resíduos não orgânicos, sobretudo os perigosos; estímulo ao uso do bicicletário; disponibilização e ampliação de equipamentos a portadores de necessidades especiais; compra de alimentos orgânicos e cultivo de horta e pomar; diversificação da matriz energética, além da modernização do sistema de esgotamento sanitário. 
No intuito de contribuir para o aperfeiçoamento da instituição, algumas sugestões de ações são apresentadas:

a) Eixo 1: dispor de sistema mecânico para irrigação dos jardins do campus; substituir todas as torneiras dos banheiros; prover sistema de reutilização da água para descargas nos banheiros; adquirir sensores de presença para iluminação dos ambientes.

b) Eixo 2: firmar parcerias com cooperativas de reciclagem de materiais diversos; criar projeto de recolhimento de pilhas e baterias; ampliar atuação do projeto "Horto Florestal Olho D'água da Bica CES/UFCG: educação ambiental, recuperação ambiental e sustentabilidade"; reativar o Comitê de Resíduos Sólidos do CES.

c) Eixo 3: promover capacitação periódica para discentes, técnico-administrativos e professores.

d) Eixo 4: identificar causas da baixa utilização do bicicletário do campus; universalizar a sinalização das rampas de acesso; equipar computadores na Biblioteca do campus com softwares de transcrição de textos para deficientes visuais.

e) Eixo 5: estudar viabilidade de diversificação da matriz energética, especialmente para a fotovoltaica; ampliar a estrutura de captação de água pluvial de forma a diminuir a extração de água do olho d'água; eliminar o uso das fossas comuns rudimentares.

f) Eixo 6: realizar licitações de obras e serviços que disponham de mecanismos que confiram vantagem para materiais sustentáveis.

g) Geral: adotar, no que couber, as ações sugeridas pelo PLS da UFCG; promover evento anual de divulgação e balanço das ações, sobretudo as desenvolvidas no âmbito da gestão socioambiental.

Desta forma, considera-se concluído o diagnóstico da universidade, seguindo os preceitos elencados pelo Manual de Gestão Socioambiental nas Universidades Públicas (2017). O Plano de Ação, entre outras coisas, prevê o reestabelecimento do Comitê Gestor dos Laboratórios do CES, de maneira que este faça as vezes da Comissão Gestora da A3P. O próximo passo, o terceiro dos seis enumerados pela cartilha, é elaborar o Plano de Gestão Socioambiental, devendo conter "os objetivos, os projetos, as atividades ou ações que serão implantadas; as metas a serem alcançadas, as medidas de monitoramento, e uma avaliação com base nos indicadores selecionados" (BRASIL, 2017a, p. 22).

\section{REFERÊNCIAS}

Araújo, S. M., Freitas, L. S., \& Rocha, V. S. G. L. (2017). Gestão Ambiental: práticas sustentáveis nos campi de uma IFES. REUNIR, 7(3), 36-50. Recuperado de http://revistas.ufcg.edu.br/reunir/index.php/uacc/article/view/672/pdf

Boff, L. (2013). Sustentabilidade: o que é, o que não é. 2a ed. Petrópolis: Vozes. 
Brasil. R. F. (2017a). Ministério do Meio Ambiente. Gestão Socioambiental nas Universidades Públicas. Brasília: MMA, 35 p. Recuperado de http://www.mma.gov.br/images/arquivo/80063/Publicacoes\%202017/universidade.pdf

Brasil. R. F. (2017b). Ministério do Meio Ambiente. Curso de Capacitação Sustentabilidade na Administração Pública. Brasília: MMA, 73 p. Recuperado de http://www.mma.gov.br/images/arquivo/80063/Curso\%20de\%20Capacitacao/Cartilha\%20for mato\%20Web.pdf

Brasil. R. F. (2010a). Lei no 12.305, de 02 de agosto de 2010. Institui a Política Nacional de Resíduos Sólidos. Brasília: Presidência da República. Recuperado de http://www.planalto.gov.br/ccivil_03/_ato2007-2010/2010/lei/l12305.htm

Brasil. R. F. (2010b). Ministério do Planejamento, Orçamento e Gestão. Instrução Normativa no 01, de 19 de janeiro de 2010. Dispõe sobre os critérios de sustentabilidade ambiental na aquisição de bens, contratação de serviços ou obras pela Administração Pública Federal direta, autárquica e fundacional. Brasília: MPOG. Recuperado de http://www.comprasnet.gov.br/legislacao/legislacaoDetalhe. asp?ctdCod=295

Brasil. R. F. (2009). Ministério do Meio Ambiente. Agenda ambiental na administração pública. 5a ed. Brasília: MMA. $100 \quad$ p. $\quad$ Recuperado de http://www.mma.gov.br/estruturas/a3p/_arquivos/cartilha_a3p_36.pdf

Brasil. R. F. (2001). Ministério do Meio Ambiente. Agenda ambiental na administração pública. Brasília: $\quad$ MMA. $\quad 80 \quad$ p. $\quad$ Recuperado de https://pactoglobalcreapr.files.wordpress.com/2010/10/a3p.pdf

CMMAD. (1991). Conselho Mundial sobre o Meio Ambiente e Desenvolvimento. RELATÓRIO BRUNDTLAND. Nosso Futuro Comum. 2a ed. Rio de Janeiro: Fundação Getúlio Vargas. Recuperado de https://pt.scribd.com/doc/12906958/Relatorio-Brundtland-Nosso-FuturoComum-Em-Portugues

Cogo, G. A. R., Oliveira, I. L., \& Tesser, D. P. (2012). Agenda Ambiental na Administração Pública (A3P): um instrumento a favor da sustentabilidade na administração pública. In: Anais... XXXII Encontro Nacional de Engenharia de Produção. Bento Gonçalves: ENEGEP. Recuperado de http://www.abepro.org.br/biblioteca/enegep2012_tn_sto_167_969_20065.pdf

Creswell, J. W. (2007). Projeto de Pesquisa. 3a ed. Porto Alegre: Artmed.

Dias, A. L. (2014). Gestão ambiental na UFBA sob a perspectiva dos eixos temáticos da A3P. 2014. 210 f. Dissertação (Mestrado) - Instituto de Humanidades, Artes e Ciências Professor Milton Santos, Universidade Federal da Bahia, Salvador. Recuperado de https://repositorio.ufba.br/ri/bitstream/ri/16634/1/Dias_A_L_Dissertacao_versao\%20final.pd $f$

Dias, G. F. (2004). Educação Ambiental: princípios e práticas. 9a ed. São Paulo: Gaia. 
Freitas, C. L., Borget, A., \& Pfitscher, E. D. (2011). Agenda Ambiental na Administração Pública: uma análise da aderência de uma IFES às diretrizes propostas pela A3P. In: Anais ... XI Colóquio Internacional Sobre Gestão Universitária na América do Sul, II Congresso Internacional IGLU. Florianópolis: IGLU. Recuperado de https://repositorio.ufsc.br/bitstream/handle/123456789/30051/7.7.pdf?sequence=>

Gondim, J. S. L. (2017). Meio ambiente e sustentabilidade no contexto do Centro de Ciências Médicas - CCM/UFPB. (Dissertação de Mestrado). Programa de Pós Graduação em Organizações Aprendentes, Universidade Federal da Paraíba, João Pessoa, PB, Brasil. Recuperado de http://tede.biblioteca.ufpb.br/bitstream/tede/9686/2/arquivototal.pdf

Kruger, S. D., Freitas, C. L., Pfitscher, E. D., Petri, S. M. (2011). Gestão Ambiental em Instituição de Ensino Superior - uma análise da aderência de uma Instituição de Ensino Superior comunitária aos objetivos da Agenda Ambiental na Administração Pública (A3P). Rev. GUAL, Florianópolis, 4(3). Recuperado de https://periodicos.ufsc.br/index.php/gual/article/view/19834535.2011v4n3p44/21979

Laville, C., Dionne, J. (1999). A construção do saber: manual de metodologia da pesquisa em ciências humanas. Belo Horizonte: Editora UFMG.

Marconi, M. A., Lakatos, E. M. (2007). Técnicas de pesquisa. 6a ed. rev. ampl. São Paulo: Atlas.

Pegorin, M. C., Santos, D. C., \& Martins, I. S. C. (2014). A Aplicação da Agenda Ambiental no Setor Público: estudo de caso em uma instituição da administração pública federal direta. In: Anais ... $X$ Congresso Nacional de Excelência em Gestão. Rio de Janeiro: CNEG. Recuperado de http://www.inovarse.org/sites/default/files/T14_0005.pdf

Sartori, S., Latrônico, F., \& Campos, L. (2014). Sustentabilidade e Desenvolvimento Sustentável: uma taxonomia no campo da literatura. Ambiente e Sociedade, 17(1), 1-22, jan./mar. Recuperado de http://www.scielo.br/pdf/asoc/v17n1/v17n1a02.pdf

Seiffert, M. E. B. (2014). Gestão ambiental: instrumentos, esferas de ação e educação ambiental. 3a ed. São Paulo: Atlas.

Viegas, S. F., Cabral, E. R. (2014). Adesão de uma Universidade Pública à Agenda Ambiental na Administração Pública - A3P. In: Anais. V Colóquio Organizações, Desenvolvimento e Sustentabilidade. Belém: CODS. Recuperado de http://revistas.unama.br/index.php/coloquio/article/view/247/pdf

Universidade Federal de Campina Grande. (2019). Plano de Logística Sustentável da UFCG. Universidade Federal de Campina Grande.

\section{COMO CITAR ESTE ARTIGO:}

Barbosa, M. DE F. N., Chaves, R. A. M., Aragão, J. M. C., Carvalho, J. R. M. DE. (2020). Gestão socioambiental no Centro de Educação e Saúde da Universidade Federal de Campina Grande: uma análise à luz da agenda ambiental na administração pública. Holos. 36(6), 1-17. 


\section{SOBRE OS AUTORES}

\section{DE F. N. BARBOSA}

Doutora em Recursos Naturais pela Universidade Federal de Campina Grande. Professora da Universidade Federal de Campina Grande. Professora do Mestrado Profissional em Administração Pública em Rede PROFIAP/UFCG. E-mail: mfnobregabarbosa@gmail.com

ORCID ID: https://orcid.org/0000-0003-3415-8829

\section{R. A. M. CHAVES}

Mestre em Administração Pública pela Universidade Federal de Campina Grande no Mestrado Profissional em Administração Pública em Rede - PROFIAP/UFCG. E-mail: adm.raiffchaves@gmail.com

ORCID ID: https://orcid.org/0000-0001-6014-1954

\section{J. M. C. ARAGÃO}

Doutora em Recursos Naturais pela Universidade Federal de Campina Grande. Doutora em Ciências Jurídicas e Sociais pela Universidade Del Museo Social Argentino. Professora da Universidade Federal de Campina Grande. Professora do Mestrado Profissional em Administração Pública em Rede - PROFIAP/UFCG. E-mail: jonicamca@gmail.com

ORCID ID: https://orcid.org/0000-0003-2983-8248

\section{J. R. M. DE CARVALHO}

Doutor em Recursos Naturais pela Universidade Federal de Campina Grande. Professor da Universidade Federal de Campina Grande. Professor do Mestrado Profissional em Administração Pública em Rede PROFIAP/UFCG. E-mail: profribamar@gmail.com

ORCID ID: https://orcid.org/0000-0003-3482-9231

Editor responsável: Francinaide de Lima Silva Nascimento

Pareceristas Ad Hoc: João Amorim e Vandervilson Carneiro

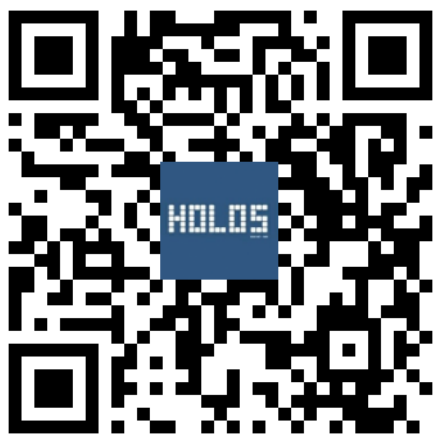

